\title{
Efficacy and safety of plasma hemodiafiltration (PHDF) in pediatric patients with multiple organ dysfunction syndrome with shock and DIC: a preliminary study
}

\author{
Hiroyuki Nagafuchi ${ }^{1 *}$, Hiroyuki Shimizu', Kaori Yamada', Kenta Shono ${ }^{1}$ and Tetsuya Ogawa ${ }^{2}$
}

\begin{abstract}
Background: Multiple organ dysfunction syndrome is the leading cause of death in pediatric intensive care units and can be very critical when combined with shock and disseminated intravascular coagulation (DIC). Currently, there is no effective treatment. We developed a new hemodiafiltration (HDF) method called plasma HDF (PHDF) that uses fresh frozen plasma as replacement fluid and investigated the safety and efficacy of this treatment.

Methods: We enrolled critically ill children with (1) a Pediatric Logistic Organ Dysfunction 2 (PELOD-2) score $\geq 14$, (2) a Japanese Ministry of Health and Welfare (JMHW) DIC score $\geq 7$, (3) a vasoactive inotropic score (VIS) $\geq 10$, and (4) a serum total protein concentration $\leq 5.0 \mathrm{~g} / \mathrm{dL}$. PHDF was performed for $5 \mathrm{~h}$ and then switched to continuous HDF. The primary endpoint was the 28-day mortality rate. Secondary endpoints included assessment of vital signs, blood test data, and fluid balance from PHDF start to day 7.

Results: Nine patients (four males and five females) between 3 days and 40 months of age, weighing $2.1-13 \mathrm{~kg}$, met the inclusion criteria. Although the median PMR was 0.94 (0.71-0.96), the 28-day mortality rate was $22.2 \%$ (2/9). One hour after the start of PHDF, there was an increase in mean arterial pressure and central venous pressure and a decrease in heart rate; by day 7, there was a significant decrease in the PELOD-2 score, the JMHW DIC score, and the VIS. Hypoproteinemia also improved the day after PHDF. Water balance was able to remain negative after day 2.

Conclusions: PHDF was found to be effective in the treatment of DIC and circulatory failure by supplementing coagulation and antithrombotic factors as well as by raising colloid osmotic pressure to increase circulating blood volume. PHDF has been shown to be a safe and useful treatment for critically ill children and has the potential to improve 28-day survival.
\end{abstract}

Keywords: Children, Plasma exchange, CRRT, MODS, DIC, Shock, Colloid osmotic pressure

\footnotetext{
* Correspondence: hnagafuchi@kcmc.jp

'Department of Critical Care Medicine, Kanagawa Children's Medical Center, Yokohama, Japan

Full list of author information is available at the end of the article
}

(c) The Author(s). 2021 Open Access This article is licensed under a Creative Commons Attribution 4.0 International License, which permits use, sharing, adaptation, distribution and reproduction in any medium or format, as long as you give appropriate credit to the original author(s) and the source, provide a link to the Creative Commons licence, and indicate if changes were made. The images or other third party material in this article are included in the article's Creative Commons licence, unless indicated otherwise in a credit line to the material. If material is not included in the article's Creative Commons licence and your intended use is not permitted by statutory regulation or exceeds the permitted use, you will need to obtain permission directly from the copyright holder. To view a copy of this licence, visit http://creativecommons.org/licenses/by/4.0/ The Creative Commons Public Domain Dedication waiver (http://creativecommons.org/publicdomain/zero/1.0/) applies to the data made available in this article, unless otherwise stated in a credit line to the data. 


\section{Background}

Multiple organ dysfunction syndrome (MODS) is a major cause of death in the intensive care unit (ICU) and often is an undesirable outcome of successful shock resuscitation [1]. MODS is defined as altered organ function in the setting of sepsis, septic shock, or systemic inflammatory response syndrome (SIRS), and shock is defined as inadequate organ perfusion even after adequate fluid resuscitation [1]. SIRS causes increased vascular permeability and leakage of plasma proteins into the tissues, which is clinically termed as capillary leak syndrome (CLS), resulting in a decrease in plasma colloid osmotic pressure (COP) and in increase in circulating blood volume that leads to fluid overload (FO) and hypotension [2]. Patients who present with hypoproteinemia despite low circulating blood volume are often unresponsive to aggressive fluid resuscitation and vasoactive drugs.

SIRS often leads to activation of the blood coagulation system by generation of thrombin, downregulation of physiological anticoagulation mechanisms, and inhibition of fibrinolysis [3], leading to disseminated intravascular coagulation (DIC) syndrome. DIC is systemic activation of coagulation, and especially in DIC with suppressed fibrinolysis [4], development of microthrombi can cause capillary obstruction and inadequate blood supply to various organs $[5,6]$.

Therefore, MODS occurs after shock with DIC, and hypoproteinemia causes extremely poor organ perfusion. Children who develop MODS with DIC, often accompanied by shock, have a high mortality rate [7, 8], with $>50 \%$ chance of dying within a week after the onset of MODS [9], but there is no effective treatment at present.

As both SIRS and DIC progress over time, the prognosis depends on the ability to improve circulatory failure as quickly as possible and maintain blood flow to organs thereafter. There is then a need to improve DIC, especially on an hourly basis, to prevent extravascular leakage, so we wondered if a technique to administer large doses of plasma proteins in fresh frozen plasma (FFP) while avoiding water loading would be needed.

Therapeutic plasma exchange (TPE) may improve systemic inflammation and DIC by reducing inflammatory mediators (cytokines) and replenishing large amounts of anticoagulant factors, resulting in improved organ function [10]. Stegmayr et al. found that for severe DIC and MODS, TPE using FFP has been reported to be effective [11]. Similarly, several reports have shown TPE to be effective for severe sepsis and MODS in pediatric patients $[12,13]$. However, TPE has many side effects, including hypernatremia, metabolic alkalosis, hypocalcemia, and decreased COP [14]. When performing TPE in adults, simultaneous hemodiafiltration (HDF) is recommended to reduce side effects [14]. However, the combination therapy (TPE + HDF) is difficult to perform in children due to the disproportionately large priming volume. Therefore, we developed the new hemodiafiltration method, plasma HDF (PHDF), which uses FFP instead of commercial replacement fluid. Although it does not remove large molecules like TPE, PHDF allows for supplementation of serum proteins, including coagulation and fibrinolytic factors, without excessive water loading and is expected to improve DIC and increase COP, then improve circulation failure and FO. Furthermore, we believed that it could reduce the adverse effects associated with high doses of FFP.

In this study, we investigated the efficacy and safety of PHDF in critically ill children with MODS with shock and DIC.

\section{Methods}

The study was conducted at the pediatric intensive care unit (PICU) of the Kanagawa Children's Medical Center (Yokohama) from January 2013 to December 2018, with the approval of the local ethics committee (1612-10). Informed consent was obtained from the patient's parents, in accordance with the principles of the Declaration of Helsinki, and personal data were anonymized.

Shock was defined as the need to use a vasopressor to maintain adequate blood pressure after sufficient infusion of fluids (20-mL/kg crystalloid), and adequate blood pressure was defined as a systolic blood pressure of 60 $\mathrm{mmHg}$ in neonates and $70 \mathrm{mmHg}$ in infants as per the American Heart Association index [15]. If adequate blood pressure could not be maintained despite volume expansion, administration of hydrocortisone $(5 \mathrm{mg} / \mathrm{kg} /$ day until the shock was reversed) and inotropes was started. Dopamine and dobutamine were the first-line inotropic agents, and epinephrine was the second-line agent. Milrinone was not used because of the risk of increased serum levels due to decreased renal function. Administrations of dopamine and dobutamine were started at $5 \mu \mathrm{g} / \mathrm{kg} / \mathrm{min}$, which was titrated up to $10 \mu \mathrm{g} /$ $\mathrm{kg} / \mathrm{min}$. Administration of epinephrine was started at $0.05 \mu \mathrm{g} / \mathrm{kg} / \mathrm{min}$, which was titrated up to $1 \mu \mathrm{g} / \mathrm{kg} / \mathrm{min}$. If hypotension was not responsive to epinephrine, vasopressin administration was started at $0.04 \mathrm{U} / \mathrm{kg} / \mathrm{h}$ and was titrated up to $0.2 \mathrm{U} / \mathrm{kg} / \mathrm{h}$.

Clinical characteristics, admission diagnosis, underlying disease, available laboratory values, vital signs, Pediatric Logistic Organ Dysfunction 2 (PELOD-2) score [16], Japan Ministry of Health and Welfare (JMHW) DIC score [17], vasopressor use (vasoactive inotropic score, VIS) [18], and ICU fluid intake and output were studied before and after PHDF. Variables collected daily were assessed for each patient on days 1, 3, 5, and 7. In particular, during PHDF, the mean arterial pressure (MAP), heart rate (HR), and central venous pressure 
(CVP) were assessed every hour, and laboratory findings (ionized calcium, sodium, bicarbonate, and lactate) were assessed every $3 \mathrm{~h}$.

The inclusion criteria were as follows: (1) MODS defined by PELOD-2 score $\geq 14$ (predicted mortality $>0.5$ ), (2) DIC defined by JMHW DIC score $\geq 7$, (3) VIS $\geq 10$ to prevent severe hypotension, and (4) hypoproteinemia, serum total protein $(\mathrm{TP}) \leq 5.0 \mathrm{~g} / \mathrm{dL}$. VIS was calculated as follows: VIS $=$ dopamine dose $(\mu \mathrm{g} / \mathrm{kg} / \mathrm{min})+$ dobutamine dose $(\mu \mathrm{g} / \mathrm{kg} / \mathrm{min})+100 \times$ epinephrine dose $(\mu \mathrm{g} / \mathrm{kg} / \mathrm{min})+10 \times$ milrinone dose $(\mu \mathrm{g} / \mathrm{kg} / \mathrm{min})+10,000$ $\times$ vasopressin dose $(\mathrm{U} / \mathrm{kg} / \mathrm{min})+100 \times$ norepinephrine dose $(\mu \mathrm{g} / \mathrm{kg} / \mathrm{min})$.

The exclusion criteria were as follows: weight $>15 \mathrm{~kg}$, patients with a history of allergic reactions to FFP, and patients with severe acute liver failure as an indication for liver transplantation.

\section{PHDF/continuous hemodiafiltration (CHDF) protocol}

Vascular access was placed in the femoral or internal jugular vein. PHDF was performed for $5 \mathrm{~h}$ per patient. The blood flow rate (QB) ranged from 2 to $5 \mathrm{~mL} / \mathrm{kg} /$ min. The replacement flow (FFP, Japanese Red Cross Society, Tokyo, Japan) rate (QS) was $10 \mathrm{~mL} / \mathrm{kg} / \mathrm{h}$ (total infusion volume $50 \mathrm{~mL} / \mathrm{kg}$ ), and the dialysate (Sublood$\mathrm{BSG}^{\circ}$, FUSO Pharmaceutical Industries Ltd., Osaka, Japan) flow rate (QD) was $200 \mathrm{~mL} / \mathrm{kg} / \mathrm{h}$ with a cellulose triacetate (CTA) membrane (UT-300S ${ }^{\oplus}$, Nipro, Osaka, Japan). Ultrafiltration was initiated after MAP, and CVP increased by $>20 \%$ from baseline levels. Nafamostat mesylate was administered as an anticoagulant at an initial dose of $0.5 \mathrm{mg} / \mathrm{kg} / \mathrm{h}$ and adjusted to maintain an activated coagulation time of 180-200 s. After PHDF, conventional CHDF with a commercial replacement solution (Sublood-BSG ${ }^{\circ}$ ) was performed by switching the three-way stopcock (Fig. 1), with a QS of $0-10 \mathrm{~mL} /$ $\mathrm{kg} / \mathrm{h}$ and a QD of $30-50 \mathrm{~mL} / \mathrm{kg} / \mathrm{h}$.

\section{Estimation}

The primary outcome was mortality at 28 days after PHDF initiation, and the secondary outcomes were changes in PELOD-2 score, JMHW score, VIS, fluid balance, vital signs (MAP and CVP), and laboratory findings during 7 days. This study had no control group, so we calculated the predicted mortality rate (PMR) on the basis of illness severity. The PMR for each child was determined using the PELOD-2 score at the start of the PHDF. One of the inclusion criteria was that PMR be $>50 \%$. We assessed whether the actual mortality rate in this study would be $>50 \%$. Changes in vital signs (MAP, $\mathrm{HR}, \mathrm{CVP}$ ) and laboratory findings (ionized calcium, sodium, bicarbonate, lactate) during the PHDF period were also evaluated. Data on vital signs were expressed as a ratio to values before the start of PHDF.

\section{Statistical analysis}

Continuous variables are expressed as medians (Q1-Q3; interquartile range). The Kruskal-Wallis test was used to compare groups of three or more continuous variables, and multiple comparisons of Steel were used for post hoc testing. The results of the analysis were considered significant for values of $p<0.05$. Statistical tests were performed by using the EZR software (Saitama Medical Center, Jichi Medical University, Saitama, Japan), a graphical user interface for R (The R Foundation for Statistical Computing, Vienna, Austria).

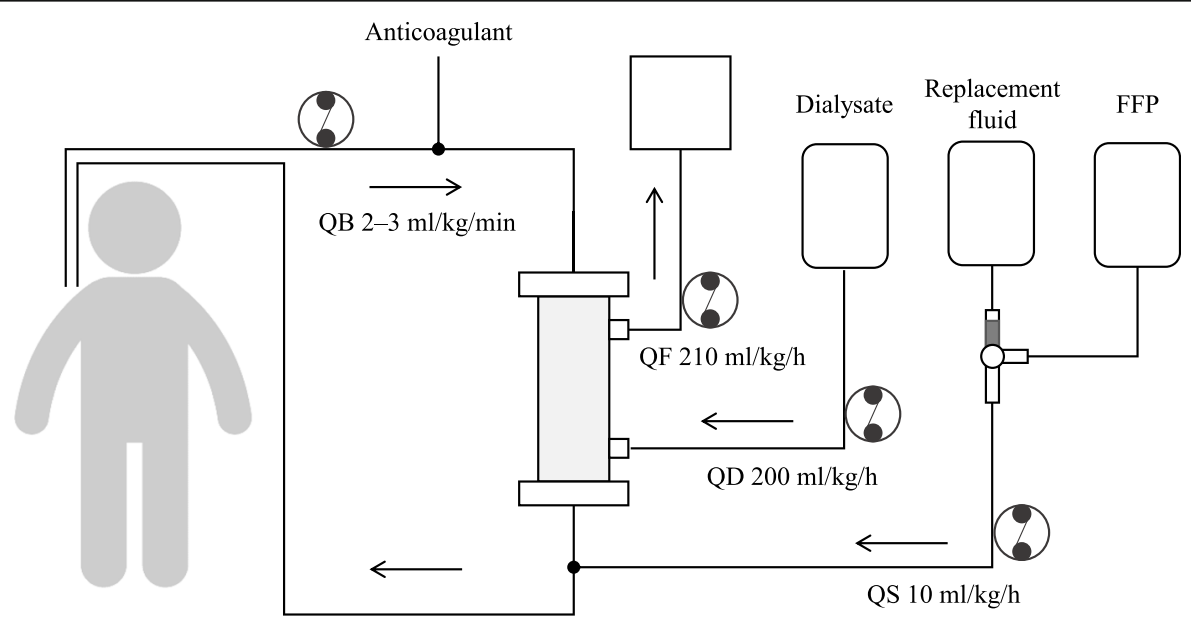

Fig. 1 The schematic circuit diagram of plasma hemodiafiltration (PHDF). PHDF is a type of hemodiafiltration with FFP as a replacement solution. $\mathrm{QB}$ ranged from 2 to $5 \mathrm{~mL} / \mathrm{kg} / \mathrm{min}$, QS rate was $10 \mathrm{~mL} / \mathrm{kg} / \mathrm{h}$, and QD was $200 \mathrm{~mL} / \mathrm{kg} / \mathrm{h}$. A zero-balance HDF was performed until blood pressure was elevated, and the QF was set at $210 \mathrm{~mL} / \mathrm{kg} / \mathrm{h}$. QB, blood flow rate; QF, filtration flow rate; QD, dialysate flow rate; QS, replacement fluid rate; FFP, fresh frozen plasma 


\section{Results}

Nine patients (four males, five females) between 3 days and 40 months of age, weighing between 2.1 and $13 \mathrm{~kg}$, met the study criteria. The patient demographics are shown in Table 1; seven of the nine patients had congenital heart disease, and four had undergone postopen heart surgery. The reasons for admission to the ICU were cardiogenic shock in three patients, septic shock in two, cardiopulmonary arrest in two, and hemorrhagic shock and encephalopathy syndrome in two. All patients required mechanical ventilation on admission to the ICU; the median time to perform PHDF and CHDF was 5.0 (4.3-5.0) and $280(74-704) \mathrm{h}$, respectively. All procedures were performed safely without serious complications.

\section{Primary outcomes}

The 28 -day mortality rate was $22.2 \%(2 / 9)$. The median PMR was 0.94 (0.71-0.96). Two patients died within 4 days of starting treatment (early deaths).

\section{Secondary outcomes}

The results of the assessment of the variables are shown in Table 2. When compared with before the treatment, significant decreases in the PELOD-2 score $(p=0.009)$, JMHW score $(p=0.004)$, and VIS $(p=0.004)$ were observed by day 7 . In addition, there was a significant improvement in water balance from day 1 to day 7 . The MAP showed a significant increase on the day after
PHDF ( $p=0.011)$, was significantly higher than before PHDF (day 0), and showed a significant decrease in the CVP on day $5(p=0.031)$. The TP level showed a significant increase on day $1(p=0.001)$. The lactate level was significantly decreased $(p=0.039)$ on day 5 . The platelet count also increased significantly on day $1(p=0.047)$, although all nine patients received platelet transfusions. Thrombin-antithrombin complex (TAT) and plasminogen activator inhibitor-1 (PAI-1) peaked on day 1 and then decreased, but did not differ significantly. On the other hand, plasmin- $\alpha 2$ plasmin inhibitor complex (PIC) decreased on day 1 , peaked on day 3 , and then tended to decrease, but no significant difference was observed. Interleukin (IL)-6 concentrations were measured on days 0,1 , and 3 in only four cases (cases $5,7,8,9$ ); in three of the four cases (cases 5, 8, 9), IL-6 concentrations tended to decrease (Fig. 2).

After the start of PHDF, MAP showed a significant increase $(p=0.015)$, and HR showed a significant decrease $(p=0.015)$ at $1 \mathrm{~h}$, and CVP showed a significant increase $(p=0.002)$ at 3 h (Fig. 3). The concentration of bicarbonate ions showed an increasing trend with time but not a significant increase, and no significant changes were observed in the concentrations of calcium, sodium, and lactate ions (Table 3). Two patients (cases 6 and 7) died early within 7 days of starting treatment; they had poorly elevated TP levels after PHDF (Fig. 4), and one of them (case 7) had an elevated IL-6 level (Fig. 2).

Table 1 Clinical details of the patients

\begin{tabular}{|c|c|c|c|c|c|c|c|c|c|}
\hline Case & 1 & 2 & 3 & 4 & 5 & 6 & 7 & 8 & 9 \\
\hline Age & $3 d$ & $5 d$ & $8 d$ & $2 \mathrm{mo}$ & $10 \mathrm{mo}$ & $12 \mathrm{mo}$ & $5 \mathrm{mo}$ & $40 \mathrm{mo}$ & $36 \mathrm{mo}$ \\
\hline Sex & $\mathrm{F}$ & M & M & M & $\mathrm{F}$ & M & $\mathrm{F}$ & $\mathrm{F}$ & M \\
\hline Weight (kg) & 2.1 & 2.1 & 2.5 & 2.6 & 5.3 & 5.8 & 7.2 & 12 & 13 \\
\hline Underlying disease & AS & $\mathrm{COA} / \mathrm{C}$ & $\mathrm{COA} / \mathrm{C}$ & TGA & TA & $\begin{array}{l}\text { Hypo RV } \\
\text { ASD } \\
\text { VSD }\end{array}$ & $(-)$ & $(-)$ & $(-)$ \\
\hline Cause of ICU admissions & CS & CS & CS & DS & DS & CS & CS & HSES & HSES \\
\hline Infection & $(-)$ & $(-)$ & $(-)$ & $(+)$ & $(+)$ & $(-)$ & $(-)$ & $(+)$ & $(+)$ \\
\hline FFP administration (ml) & 120 & 120 & 120 & 120 & 240 & 240 & 480 & 720 & 720 \\
\hline $\mathrm{QB}(\mathrm{ml} / \mathrm{min})$ & 12 & 12 & 10 & 12 & 30 & 25 & 20 & 40 & 40 \\
\hline $\mathrm{QD}(\mathrm{ml} / \mathrm{h})$ & 500 & 500 & 500 & 500 & 1000 & 1000 & 1500 & 2000 & 2000 \\
\hline Hemofilter & UT300S & UT300S & UT300S & UT300S & UT300S & UT300S & UT300S & UT700S & UT700S \\
\hline Duration of PHDF (h) & 5 & 5 & 5.5 & 5 & 5 & 4 & 5 & 4.5 & 4 \\
\hline Duration of CHDF (h) & 935 & 56 & 664 & 280 & 744 & 86 & 61 & 589 & 132 \\
\hline PELOD-2 score at day 0 & 22 & 14 & 23 & 16 & 14 & 20 & 21 & 20 & 17 \\
\hline PMR by PELOD-2 score & 0.98 & 0.49 & 0.98 & 0.71 & 0.49 & 0.94 & 0.96 & 0.94 & 0.80 \\
\hline $\begin{array}{l}\text { 28-day outcome } \\
\text { (the day of death) }\end{array}$ & Survival & Survival & Survival & Survival & Survival & Death (4) & Death (3) & Survival & Survival \\
\hline
\end{tabular}

AS arterial stenosis, CoA/C coarctation complex, TGA transposition of the great arteries, TA truncus arteriosus, $R V$ right ventricle, $A S D$ atrial septal defect, VSD ventricular septal defect, CS cardiogenic shock, DS distributive shock, HSES hemorrhagic shock and encephalopathy, PMR predicted mortality rate, QB blood flow rate, $Q D$ dialysate flow rate, PHDF plasma hemodiafiltration, CHDF continuous hemodiafiltration, PELOD-2 Pediatric Logistic Organ Dysfunction 2 
Table 2 Changes in clinical scores, vital signs, and laboratory findings

\begin{tabular}{|c|c|c|c|c|c|c|}
\hline Variables & & Day 0 & Day 1 & Day 3 & Day 5 & Day 7 \\
\hline PELOD-2 score & & 20 [15-22] & 16 [9.5-18] & 13 [9.0-18] & $10^{*}[9.0-14]$ & $9.0^{*}[8.0-14]$ \\
\hline VIS score & & 15 [13-35] & 10 [6.0-17] & $9.0^{*}[6.0-15]$ & $4.5[2.5-17]$ & $3.0^{*}[2.0-7.4]$ \\
\hline LMHW score & & 10 [8.0-13] & $7.0^{*}[5.5-8.5]$ & $7.0^{*}[5.0-8.5]$ & 7.0* [4.0-7.0] & $6.0^{*}[3.0-7.0]$ \\
\hline MAP & & 1.0 & $1.5^{*}[1.1-1.8]$ & $1.2[1.0-1.8]$ & $1.8^{*}[1.5-2.0]$ & $1.6^{*}[1.4-2.1]$ \\
\hline CVP & & 1.0 & $1.1[0.8-1.8]$ & $1.0[0.6-1.5]$ & $0.7^{*}[0.4-1.1]$ & $0.6^{*}[0.4-0.9]$ \\
\hline Urine volume & $(\mathrm{mL} / \mathrm{kg} / \mathrm{h})$ & $0.3[0.2-0.5]$ & $0.1[0.1-1.0]$ & $0.3[0.1-0.4]$ & $0.2[0.1-0.7]$ & $1.1[0.1-1.8]$ \\
\hline Water balance & $(\%)$ & 16 [14-24] & $3.7^{*}[1.8-11]$ & $4.1^{*}[1.6-8.8]$ & $3.1^{*}[7.2-1.2]$ & $1.6^{*}[3.3-0.5]$ \\
\hline $\mathrm{TP}$ & $(\mathrm{g} / \mathrm{dL})$ & $4.5[3.5-4.8]$ & $7.4^{*}[6.8-8.1]$ & $6.9^{*}[5.9-8.2]$ & $7.2^{*}[6.4-7.8]$ & $7.3^{*}[5.9-7.6]$ \\
\hline Lactate & $(\mathrm{mmol} / \mathrm{L})$ & $7.3[4.1-16]$ & 5.3 [3.6-10] & $4.1[2.6-8.2]$ & $2.8^{*}[1.5-4.8]$ & $1.8^{*}[1.4-3.7]$ \\
\hline PLT & $\left(\times 10^{4}\right)$ & $4.6[3.1-6.8]$ & $9.9^{*}[6.6-16]$ & $11.7^{*}[5.6-20]$ & 6.5 [5.6-114] & $12^{*}[9.3-21]$ \\
\hline TAT & $(\mathrm{ng} / \mathrm{mL})$ & 38.1 [24.4-450] & 89.6 [13.6-154] & 28.4 [10.8-77.0] & $19.4[9.7-37.0]$ & 9.5 [5.6-20.0] \\
\hline $\mathrm{PIC}$ & $(\mathrm{pg} / \mathrm{mL})$ & $3.6[0.85-11.0]$ & $3.1[0.58-6.2]$ & 8.8 [1.40-11.2] & $6.0[2.5-16.6]$ & $4.9[3.0-8.0]$ \\
\hline PAI-1 & (ng/mL) & 379 [174-1240] & 531 [372-848] & 322 [102-616] & 130 [27.7-173] & $34.2[23.7-460]$ \\
\hline
\end{tabular}

Data are presented as median [interquartile range]. MAP and CVP are expressed as a ratio to the value at day 0

PELOD-2 Pediatric Logistic Organ Dysfunction-2, VIS vasoactive inotropic score, JMHW Japanese Ministry of Health and Welfare, MAP mean arterial pressure, CVP central venous pressure, TP total protein, PLT platelet count, TAT thrombin-antithrombin complex, PIC plasmin a2-plasmin inhibitor complex, PAI-1 plasminogen activator inhibitor-1

${ }^{*} p<0.05$ compared with before the treatment (day 0) by Kruskal-Wallis test and post hoc Steel tests

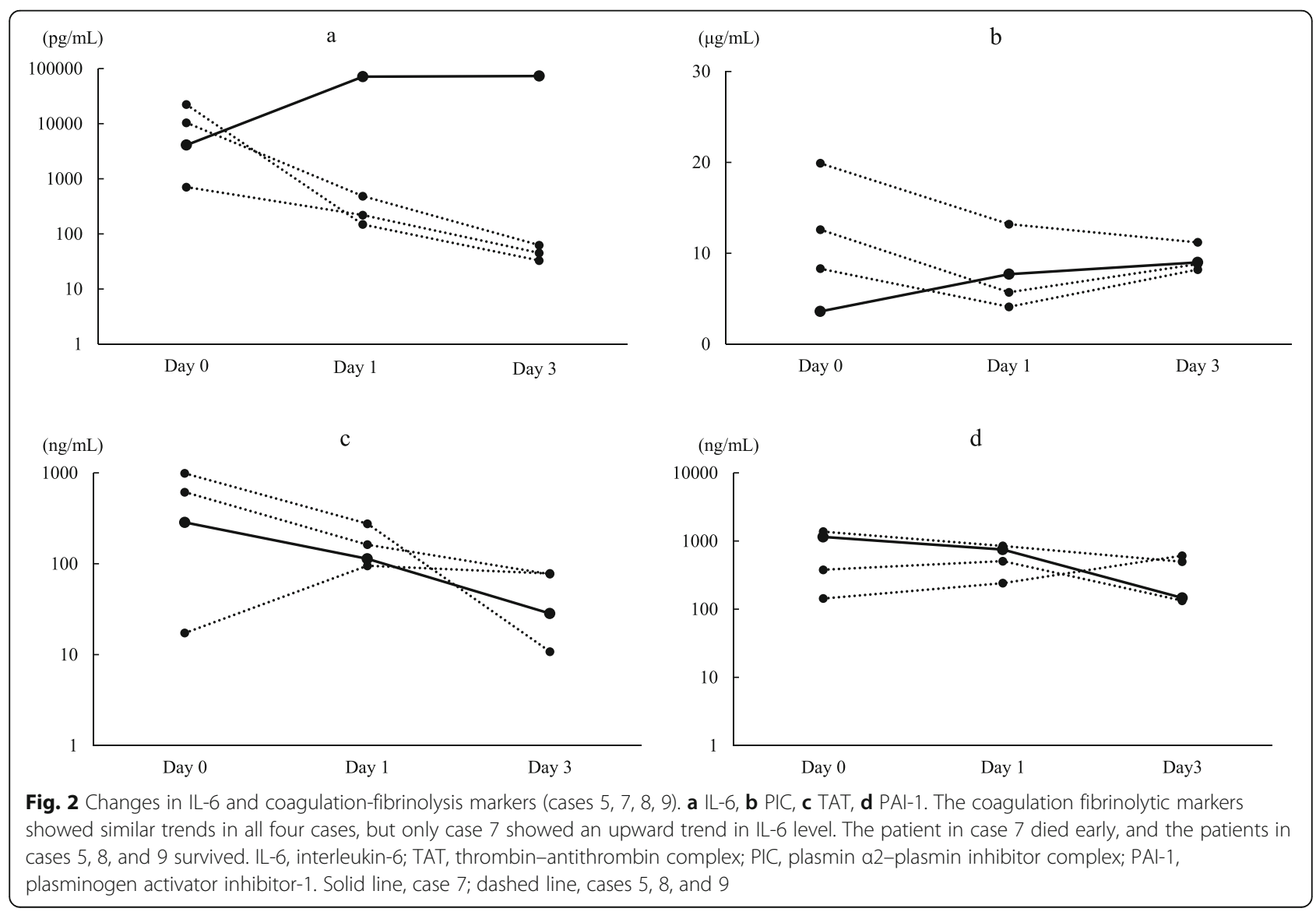


$\mathrm{a}$

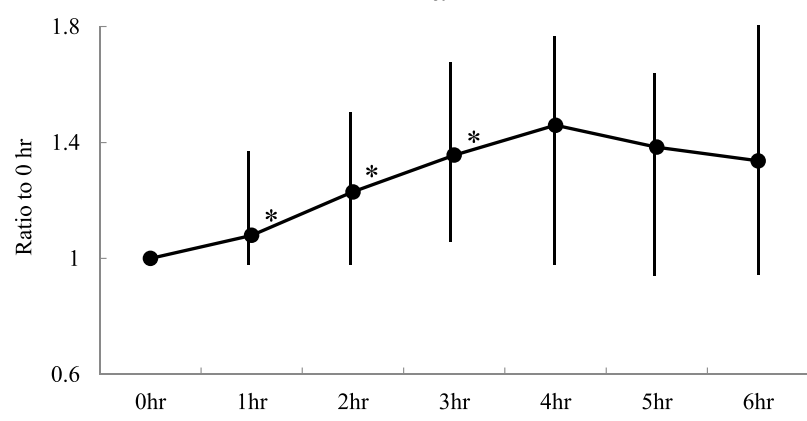

C

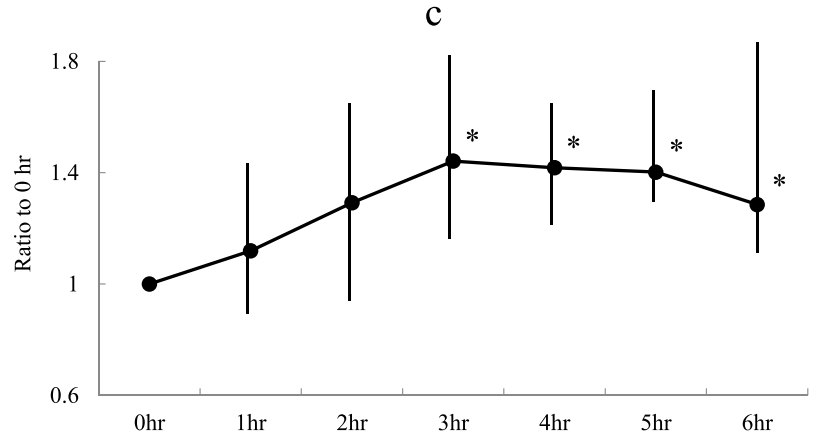

b

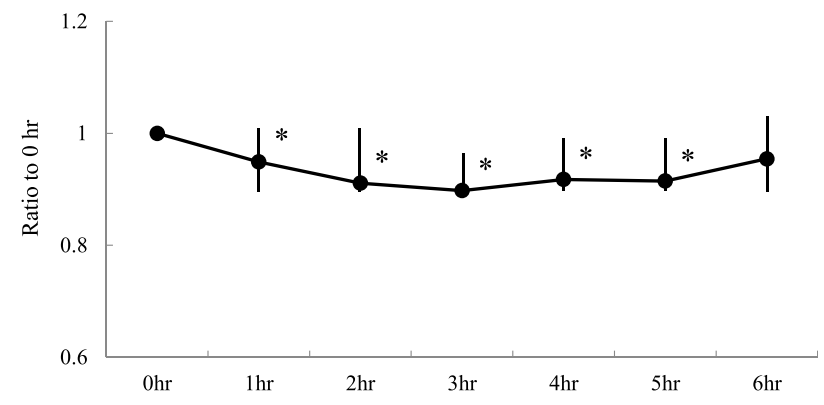

Fig. 3 Changes in vital sign markers during plasma hemodiafiltration. a MAP. b HR. c CVP. Both MAP and CVP increased, and HR showed a downward trend until near the 4th hour of treatment, after which MAP and CVP showed a moderate downward trend. Data are expressed as a ratio to the value before starting plasma hemodiafiltration. MAP, mean arterial pressure; HR, heart rate; CVP, central venous pressure. ${ }^{*} p<0.05$ compared with before the treatment by Kruskal-Wallis test and post hoc Steel tests

\section{Adverse events}

No serious adverse events, such as anaphylaxis, hypotension, or hypocalcemia, were observed during the PHDF therapy. Patients were cared for under a radiant warmer or electric blanket, but all patients presented with mild hypothermia $\left(32-35{ }^{\circ} \mathrm{C}\right)$. However, there were no serious adverse events associated with hypothermia.

\section{Discussion}

This is the first pilot study to evaluate the clinical efficacy of PHDF therapy, an HDF therapy with FFP as a replacement fluid, in pediatric patients with MODS with shock and DIC who have a $>50 \%$ chance of early death. PHDF was safe to perform in all the patients, and during the 28-day observation period, only two $(22.2 \%)$ of the nine patients died, which suggests that PHDF could provide a treatment option for critically ill pediatric patients who have not previously had a promising treatment option.

Pediatric patients with MODS with shock and DIC have previously been found to be extremely ill $[19,20]$ and were treated with high-dose fluids, high-dose catecholamines, and steroids, but often with little or no effect and early death [19, 21]. Large doses of crystalloid are almost always administered to patients in shock, but with increased vascular permeability, the administered crystalloid only leaks outside the vessel and does not increase intravascular volume, causing FO. We hypothesized that the essence of this pathology is that prolonged tissue hypoperfusion due to persistent COP depression leads to irreversible organ failure. Extravascular fluid leakage becomes edema, which further exacerbates tissue hypoperfusion, and consequently, the edema itself also contributes to progression of organ failure. Therefore,

Table 3 Changes in ionized calcium, sodium, bicarbonate ion, and lactate during plasma hemodiafiltration

\begin{tabular}{lllll}
\hline & & Pre & $\mathbf{3 h}$ & $\mathbf{6} \mathbf{h}$ \\
\hline lonized calcium & $(\mathrm{mmol} / \mathrm{L})$ & $1.07[0.81-1.10]$ & $1.04[1.02-1.11]$ & $1.13[1.07-1.19]$ \\
Sodium & $(\mathrm{mmol} / \mathrm{L})$ & $141[133-146]$ & $144[136-147]$ & $142[137-144]$ \\
Bicarbonate $i o n$ & $(\mathrm{mmol} / \mathrm{L})$ & $18.6[16.8-22.8]$ & $21.6[18.9-23.3]$ & $23.1[18.9-24.9]$ \\
Lactate & $(\mathrm{mmol} / \mathrm{L})$ & $7.3[4.1-15.5]$ & $7.3[3.4-10.1]$ & $6.9[3.6-11.0]$ \\
\hline
\end{tabular}




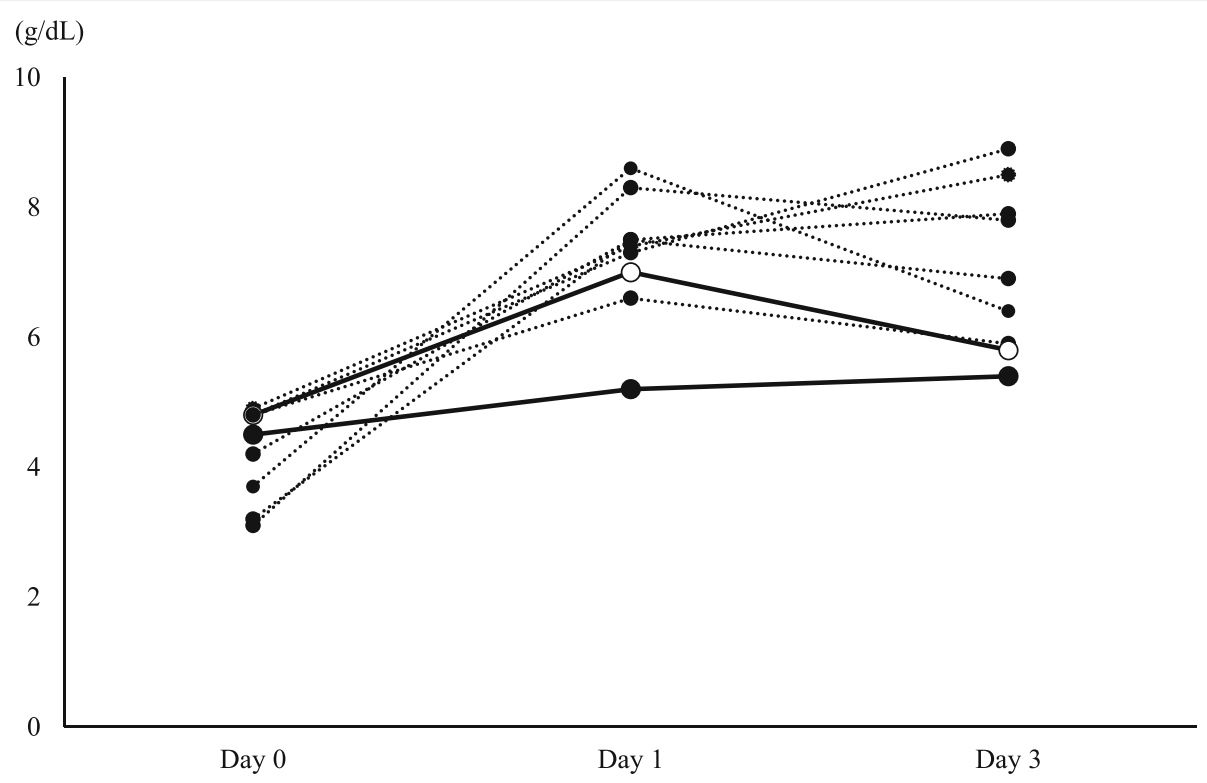

Fig. 4 Changes in serum protein levels in each case from the start of treatment to day 3. Data are expressed as a ratio to the value before starting plasma hemodiafiltration. The two cases of early death (cases 6 and 7) had the lowest rate of increase in protein levels on day 1 and showed a downward trend on day 3. Solid line, cases 6 (blotting out) and 7; dashed line, all other cases

we thought that if we could increase COP before irreversible organ failure occurred, organ blood flow could be maintained and organ failure could be avoided without exacerbation of edema.

Underlying the pathogenesis of pediatric MODS with shock and DIC is a high degree of SIRS and increased vascular permeability, which causes leakage of proteins outside of the blood vessels and establishment of severe CLS [9]. Although administration of steroids and gamma-globulin is expected to have a certain effect on CLS, the effect takes time to develop, which may lead to irreversible organ failure in the meantime.

Therefore, we thought it would be possible to increase COP if we could administer a large amount of protein in a short period of time by minimizing the amount of added water, so we devised a method of limiting the water load by using FFP as a replacement fluid for HDF (PHDF), which is one of the blood purification therapies. Furthermore, PHDF could reduce the side effects associated with large doses of FFP by using dialysis therapy. One hour after the start of PHDF, HR decreased despite the increase in CVP and MAP, suggesting an increase in effective circulating blood volume. After completion of PHDF, we continued to perform CHDF. Thereafter, CVP peaked on day 1 , showed a decreasing trend, and the dose of catecholamines also decreased, suggesting that the circulating blood volume was maintained within an appropriate range.

On the day after PHDF, TP increased to 1.6 (1.4-2.3) times relative to the level before the start of PHDF, and then did not decline until day 7 in most cases, although the rate of increase in TP levels after PHDF was lower in the two patients who died early. PHDF was shown to be a powerful tool for elevating COP in pediatric critically ill patients, but the patients in whom COP did not increase could not survive. Further studies on FFP dosage and timing of treatment initiation are needed to maximize the therapeutic benefit. FO is an independent prognostic factor in pediatric patients with multiple organ failure [22]; a negative fluid balance by day 3 is associated with an improved prognosis according to a previous report [23]. In our study, a negative fluid balance on day 2 suggested that PHDF could improve FO and may be an effective tool for treating children with FO.

SIRS not only causes CLS, which increases vascular permeability and leads to circulatory failure (shock) due to reduced COP, but also causes systemic coagulopathy, i.e., DIC. In particular, suppressed-fibrinolytic-type DIC, in which TAT and PAI-1 are markedly increased but PIC is only mildly increased, is associated with increased thrombus formation and a marked decrease in organ blood flow [6]. All nine patients in the present study presented with suppressed-fibrinolytic-type DIC, which was considered to be an exacerbating factor for tissue hypoperfusion. After PHDF, TAT, and PAI-1 showed a downward trend and the LMHW DIC score showed a downward trend, indicating that PHDF was also effective against suppressed fibrinolytic-type DIC. However, in cases of death (case 7), TAT and PAI-1 showed a downward trend, but IL- 6 showed an upward trend, 
confirming that control of DIC alone is not sufficient to improve the disease and that control of SIRS is also necessary in some cases.

Blood purification for critically ill patients has been performed for renal replacement therapy and removal of humoral mediators but has not been shown to improve outcomes significantly. TPE can replace coagulation factors in addition to cytokine removal [24], has been shown to be effective in MODS with DIC, and has demonstrated benefit in thrombocytopenia-associated multiorgan failure in children [25]. However, ultrafiltration is not possible with TPE, which may worsen FO. TPE may also exacerbate metabolic alkalosis, hypernatremia, and hypocalcemia associated with large amounts of FFP as well as exacerbate CLS due to reduced COP. For this reason, it is recommended that when PE is performed, HDF should be performed at the same time [14]. However, the combination of PE and HDF increases the extracorporeal circulating volume, which makes it dangerous to do so in critically ill children [26].

PHDF is a kind of HDF that uses FFP as replacement fluid. In this study, we used the UT-S series ${ }^{\circ}$ of CTA membranes, a high cutoff (HCO) filter with an average pore size of $7.5 \mathrm{~nm}$ and a molecular weight cutoff of 55 $\mathrm{kDa}$. Although continuous renal replacement therapies using $\mathrm{HCO}$ membranes have been reported to effectively remove inflammatory mediators and improve the hemodynamics of septic patients $[27,28]$, since IL-6 clearance is defined by the filtration rate, the clearance range in this study was $7-45 \mathrm{~mL} / \mathrm{min}(\mathrm{QF}=200+10$ $\mathrm{ml} / \mathrm{kg} / \mathrm{h}$, weight $2.1-13 \mathrm{~kg}$ ) at the highest, suggesting that cytokine removal by PHDF had little effect on blood levels. However, three of the four patients whose blood levels of IL- 6 were measured showed a decrease in IL-6 levels on the day after PHDF. This finding may be because PHDF ameliorated MODS and, consequently, improved SIRS. However, because some patients, such as the patient in case 7, do not show a decrease in IL-6, we need to consider protocols using cytokine-adsorbing hemofilters, such as AN69-ST membranes, to increase the amount of cytokine removal in the future.

\section{Limitation}

This study had some limitations. First, because the study included extremely sick patients, the severity of the disease varied, and various treatments were administered prior to the initiation of PHDF, all of which may have influenced the effectiveness of those treatments. The number of cases in future studies needs to be increased to confirm the usefulness of the study findings. Second, because this was a single-center pilot study without a control group, randomized controlled trials are needed to confirm a benefit. However, the study is significant because it provided a treatment for patients with a predicted mortality rate $>50 \%$. Third, although no short-term adverse effects were observed with FFP, longterm adverse effects, such as viral infections, need to be further investigated. Fourth, if elevated COP is the most important factor in the efficacy of PHDF, then, an albumin solution could be used instead of FFP, and further studies with PHDF using an albumin solution should be conducted in the future.

\section{Conclusions}

PHDF seems to have found to be effective in the treatment of DIC and circulatory failure by supplementing coagulation and antithrombotic factors, as well as by raising COP to increase circulating blood volume. As a result, PHDF may improve organ function and reduce mortality in children with severe MODS.

\section{Abbreviations \\ AS: Arterial stenosis; ASD: Atrial septal defect; CHDF: Continuous hemodiafiltration; CLS: Capillary leak syndrome; COA/C: Coarctation complex; COP: Colloid osmotic pressure; CS: Cardiogenic shock; CTA: Cellulose triacetate; CVP: Central venous pressure; DIC: Disseminated intravascular coagulation; DS: Distributive shock; FFP: Fresh frozen plasma; FO: Fluid overload; HCO: High cutoff; HDF: Hemodiafiltration; HR: Heart rate; HSES: Hemorrhagic shock and encephalopathy; ICU: Intensive care unit; JMHW: Japanese Ministry of Health and Welfare; MAP: Mean arterial pressure; MODS: Multiple organ dysfunction syndrome; PAI-1: Plasminogen activator inhibitor-1; PELOD-2: Pediatric Logistic Organ Dysfunction 2; PHDF: Plasma hemodiafiltration; PIC: Plasmin-a2 plasmin inhibitor complex; PICU: Pediatric intensive care unit; PMR: Predicted mortality rate; QB: Blood flow rate; QD: Dialysate flow rate; QS: Replacement flow rate; RV: Right ventricle; SIRS: Systemic inflammatory response syndrome; SMR: Standardized mortality rate; TA: Truncus arteriosus; TAT: Thrombin-antithrombin complex; TGA: Transposition of the great arteries; TP: Total protein; TPE: Therapeutic plasma exchange; VIS: Vasoactive inotropic score; VSD: Ventricular septal defect}

\section{Acknowledgements}

The authors thank all PICU staff, registered patients, and the patients' families. The authors also thank Enago (www.enago.jp) for the English language review.

\section{Authors' contributions}

HN wrote the initial draft of the manuscript. HS, KY, and KS managed the patients during this study. TO supervised the project and was in charge of the overall direction and planning. All authors discussed the results and commented on the manuscript. The authors read and approved the final manuscript.

\section{Funding}

Not applicable.

\section{Availability of data and materials}

The datasets analyzed during the current study are available from the corresponding author on reasonable request.

\section{Declarations}

Ethics approval and consent to participate

This study was approved by the Ethics Committee of Kanagawa Children's Medical Center (1612-10) and according to the principles of the Declaration of Helsinki, informed consent was obtained from the patient's parents, and personal data of patients were rendered anonymous. 


\section{Competing interests}

The authors declare that they have no competing interests.

\section{Author details}

'Department of Critical Care Medicine, Kanagawa Children's Medical Center, Yokohama, Japan. ${ }^{2}$ Division of Blood Purification and Nephrology, Tokyo Women's Medical University Medical Center East, Tokyo, Japan.

Received: 21 January 2021 Accepted: 29 March 2021

Published online: 07 April 2021

\section{References}

1. Johnson D, Mayers I. Multiple organ dysfunction syndrome: a narrative review. Can J Anesth. 2001;48(5):502-9. https://doi.org/10.1007/BF03028318.

2. Su J, Zhang Y, Hu W. The current opinions of capillary leak syndrome. Open J Clin Diagn. 2015;05(01):14-9. https://doi.org/10.4236/ojcd.2015.51003.

3. Levi M, Keller T, van Gorp E, ten Cate H. Infection and inflammation and the coagulation system. Cardiovasc Res. 2003;60(1):26-39. https://doi.org/1 0.1016/S0008-6363(02)00857-X.

4. Asakura $\mathrm{H}$. Classifying types of disseminated intravascular coagulation: clinical and animal models. J Intensive Care. 2014;2(1):20. https://doi.org/1 0.1186/2052-0492-2-20.

5. Levi M, Ten Cate H. Disseminated intravascular coagulation. N Engl J Med. 1999:341(8):586-92. https://doi.org/10.1056/NEJM199908193410807.

6. Levi M. Disseminated intravascular coagulation. Crit Care Med. 2007;35(9): 2191-5. https://doi.org/10.1097/01.CCM.0000281468.94108.4B.

7. Gando S, Kameue T, Nanzaki S, Nakanishi Y. Disseminated intravascular coagulation is a frequent complication of systemic inflammatory response syndrome. Thromb Haemost. 1996;75(2):224-8.

8. Gando S, Kameue T, Matsuda N, Hayakawa M, Ishitani T, Morimoto Y, et al. Combined activation of coagulation and inflammation has an important role in multiple organ dysfunction and poor outcome after severe trauma. Thromb Haemost. 2002;88(6):943-9.

9. Weiss SL, Balamuth F, Hensley J, Fitzgerald JC, Bush J, Nadkarni VM, et al. The epidemiology of hospital death following pediatric severe sepsis: when, why, and how children with sepsis die. Pediatr Crit Care Med. 2017;18(9): 823-30. https://doi.org/10.1097/PCC.0000000000001222.

10. Schwartz J, Padmanabhan A, Aqui N, Balogun RA, Connelly-Smith L, Delaney $\mathrm{M}$, et al. Guidelines on the use of therapeutic apheresis in clinical practice-evidence-based approach from the writing committee of the American Society for Apheresis: The Seventh Special Issue. J Clin Apher. 2016;31(3):149-62. https://doi.org/10.1002/jca.21470.

11. Stegmayr BG, Banga R, Berggren L, Norda R, Rydvall A, Vikerfors T. Plasma exchange as rescue therapy in multiple organ failure including acute renal failure. Crit Care Med. 2003;31(6):1730-6. https://doi.org/10.1097/01.CCM. 0000064742.00981 .14$.

12. Kawai Y, Cornell TT, Cooley EG, Beckman CN, Baldridge PK, Mottes TA, et al. Therapeutic plasma exchange may improve hemodynamics and organ failure among children with sepsis-induced multiple organ dysfunction syndrome receiving extracorporeal life support. Pediatr Crit Care Med. 2015; 16(4):366-74. https://doi.org/10.1097/PCC.0000000000000351.

13. Lima LM, McCracken CE, Fortenberry JD, Hebbar KB. Use of plasma exchange in pediatric severe sepsis in children's hospitals. J Crit Care. 2018; 45:114-20. https://doi.org/10.1016/j.jcrc.2018.01.028.

14. Sadahiro T, Hirasawa H, Oda S, Shiga H, Nakanishi K, Kitamura N, et al. Usefulness of plasma exchange plus continuous hemodiafiltration to reduce adverse effects associated with plasma exchange in patients with acute liver failure. Crit Care Med. 2001;29(7):1386-92. https://doi.org/10.1097/0000324 6-200107000-00014.

15. American Heart Association. Systematic approach to the seriously ill or injured child. In: Chameides L, Samson RA, Schexnayder SM, Hazinski MF, editors. Pediatric advanced life aupport provider manual. Dallas: American Heart Association; 2011. p. 7-30.

16. Leteurtre S, Duhamel A, Salleron J, Grandbastien B, Lacroix J, Leclerc F, et al. PELOD-2: an update of the pediatric logistic organ dysfunction score. Crit Care Med. 2013;41(7):1761-73. https://doi.org/10.1097/CCM. 0b013e31828a2bbd

17. Kobayashi N, Maegawa K, Takada M, Tanaka H, Gonmori H. Criteria for diagnosis of DIC based on the analysis of clinical and laboratory findings in 345 DIC patients collected by the Research Committee on DIC in Japan. Bibl Haematol. 1987:49:265-75.
18. Gaies MG, Gurney JG, Yen AH, Napoli ML, Gajarski RJ, Ohye RG, et al. Vasoactive-inotropic score as a predictor of morbidity and mortality in infants after cardiopulmonary bypass. Pediatr Crit Care Med. 2010;11(2):234-8. https:// doi.org/10.1097/PCC.0b013e3181b806fc.

19. Typpo KV, Petersen NJ, Hallman DM, Markovitz BP, Mariscalco MM. Day 1 multiple organ dysfunction syndrome is associated with poor functional outcome and mortality in the pediatric intensive care unit. Pediatr Crit Care Med. 2009;10(5):562-70. https://doi.org/10.1097/PCC.0b013e3181a64be1.

20. Watson RS, Crow SS, Hartman ME, Lacroix J, Odetola FO. Epidemiology and outcomes of pediatric multiple organ dysfunction syndrome. Pediatr Crit Care Med. 2017;18(3_suppl Suppl 1):S4-S16. https://doi.org/10.1097/PCC. 0000000000001047.

21. Leclerc F, Leteurtre S, Duhamel A, Grandbastien B, Proulx F, Martinot A, et al. Cumulative influence of organ dysfunctions and septic state on mortality of critically ill children. Am J Respir Crit Care Med. 2005;171(4):34853. https://doi.org/10.1164/rccm.200405-6300C.

22. Alobaidi R, Morgan C, Basu RK, Stenson E, Featherstone R, Majumdar SR, et al. Association between fluid balance and outcomes in critically ill children: a systematic review and meta-analysis. JAMA Pediatr. 2018;172(3): 257-68. https://doi.org/10.1001/jamapediatrics.2017.4540.

23. Alsous F, Khamiees M, DeGirolamo A, Amoateng-Adjepong Y, Manthous CA. Negative fluid balance predicts survival in patients with septic shock: a retrospective pilot study. Chest. 2000;117(6):1749-54. https://doi.org/10.13 78/chest.117.6.1749.

24. Hirasawa H, Sugai T, Oda S, Shiga H, Matsuda K, Ueno H, et al. Efficacy and limitation of apheresis therapy in critical care. Ther Apher. 1997;1(3):228-32. https://doi.org/10.1111/j.1744-9987.1997.tb00143.x.

25. Nguyen TC, Han YY, Kiss JE, Hall MW, Hassett AC, Jaffe R, et al. Intensive plasma exchange increases a disintegrin and metalloprotease with thrombospondin motifs-13 activity and reverses organ dysfunction in children with thrombocytopenia-associated multiple organ failure. Crit Care Med. 2008;36(10):2878-87. https://doi.org/10.1097/CCM.0b013e318186aa49.

26. Stefanutti C, Lanti A, Di Giacomo S, Mareri M, De Lorenzo F, Landolfo A, et al. Therapeutic apheresis in low weight patients: technical feasibility, tolerance, compliance, and risks. Transfus Apher Sci. 2004;31(1):3-10. https:// doi.org/10.1016/j.transci.2004.01.010.

27. Morgera S, Slowinski T, Melzer C, Sobottke V, Vargas-Hein O, Volk T, et al. Renal replacement therapy with high-cutoff hemofilters: impact of convection and diffusion on cytokine clearances and protein status. Am J Kidney Dis. 2004;43(3):444-53. https://doi.org/10.1053/j.ajkd.2003.11.006.

28. Chelazzi C, Mancinelli P, Villa G, Romagnoli S, De Gaudio AR. Effect of continuous high cutoff hemodialysis on vascular permeability of septic patients with acute kidney injury. J Crit Care. 2015;30(3):644-5. https://doi. org/10.1016/j.jcrc.2015.03.012.

\section{Publisher's Note}

Springer Nature remains neutral with regard to jurisdictional claims in published maps and institutional affiliations.
Ready to submit your research? Choose BMC and benefit from:

- fast, convenient online submission

- thorough peer review by experienced researchers in your field

- rapid publication on acceptance

- support for research data, including large and complex data types

- gold Open Access which fosters wider collaboration and increased citations

- maximum visibility for your research: over $100 \mathrm{M}$ website views per year

At $\mathrm{BMC}$, research is always in progress.

Learn more biomedcentral.com/submissions 